\title{
Nobel Prize 2019 pays tribute to translational physiology on oxygen sensing
}

\author{
Armin Kurtz ${ }^{1}$ \\ Published online: 9 November 2019 \\ (C) Springer-Verlag GmbH Germany, part of Springer Nature 2019
}

The Nobel Prize in Physiology or Medicine is the first Nobel award announced this year. In the past, the "or" between the two subjects was true alternatives in most cases. This year the Prize honors fundamental discoveries in a field linking physiology to medicine, which we know as translational physiology. The Nobel Prize 2019 in Physiology (or) Medicine goes to William Kaelin Jr, Sir Peter Ratcliffe, and Gregg Semenza. These researchers are honored for their groundbreaking work on molecular cellular oxygen sensing - or speaking in more detail-for unravelling the cellular pathways along which a reduction of the pericellular oxygen tension leads to the activation of gene transcription. Their work started out from the originally rather elusive hormone erythropoietin (EPO), which is the essential humoral activating regulator of erythropoiesis. It was already known in the 70th of the last century that EPO is produced but not stored by the kidneys and that its production is stimulated by anemia or arterial hypoxia as it occurs at higher altitudes or in states of limited alveolar diffusion. Later, renal peritubular fibroblasts were identified as production sites for EPO and EPO gene transcription was recognized as the essential control process for EPO production. Interstitial hypoxia, due to anemia or arterial hypoxia reducing the oxygen delivery to the kidneys, would then somehow lead to the transcription of the EPO gene that finally would activate erythropoiesis and increase the oxygen transport capacity of the blood [3].

Completely unclear and speculative at that time was the functional link between hypoxia and the activation of EPO gene transcription. The three Nobel laureates more or less independently discovered the three key molecular elements of this hypoxia signaling process.

Armin Kurtz

armin.kurtz@ur.de

1 Physiologisches Institut der Universität Regensburg, 93053 Regensburg, Germany
First, a new heterodimeric transcription factor that appeared during hypoxia and bound to the EPO gene enhancer was discovered and characterized. This new transcription factor - termed hypoxia-inducible factor (HIF) - was found to be constantly produced but turned out to be rather unstable at normal oxygen tensions [7].

A second essential finding was that the instability of HIF resulted from rapid proteasomal degradation that was guided by the ubiquitin-ligase von Hippel Lindau protein (vHL) [5].

The third key finding, which is the real core finding of the oxygen sensing process, was that binding of HIF to vHL required hydroxylation of two prolyl residues in the HIF- $\alpha$ subunit. This hydroxylation process, which is catalyzed by specific prolyl hydroxylases, requires 2-oxoglutarate and oxygen. At lower oxygen tensions (hypoxia), hydroxylation of the HIF- $\alpha$ subunit is reduced and HIF-protein becomes stable and transcriptionally active $[1,2]$.

Certainly, these findings would have attracted less attention, if these events would be specific for special renal cells or for the EPO gene. A major fourth breakthrough therefore was the finding that the "HIF" mechanism is not specific for $\mathrm{EPO}$ or for special renal cells, but is instead a generally working mechanism by which hypoxia triggers a number of HIFsusceptible genes in almost all cells of the body [4, 8].

What most of these genes have in common is that their encoded proteins help cells or organs to cope with the detrimental consequences of insufficient oxygen supply. Well known in this context are glycolytic enzymes or vascular endothelial growth factor (VEGF) which drives neovascularization of hypoxic tissues.

In summary, the three Nobel laureates in conjunction discovered a novel and very fundamental signaling pathway that helps us as strictly oxygen-dependent beings to survive episodes of reduced oxygen supply to our organs. It should be noted that Kaelin, Ratcliffe, and Semenza by educational training are not basic scientists such as cell or molecular biologists but instead are active clinicians, (oncologist, nephrologist, and pediatrician). No doubt, the clinical background of 
the Nobel laureates also encouraged the translational aspects of their research. Meanwhile, pharmaceutical inhibitors of prolyl hydroxylases have been developed that "mimic" states of cellular hypoxia and thus overcome insufficient EPO production in states of kidney disease. Another example is the development of HIF-antagonists to slow down cancer growth.

It is obvious that the Nobel laureates started with an original physiological question, namely, how can an organism, organ, or cell sense hypoxia and directly transmit the results of oxygen sensing into transcriptional gene activity. Pflügers Archiv-European Journal of Physiology always paid and still pays major attention to this topic. A recently published special issue of our journal (vol 468, issue 1) in 2016 was indeed devoted to "Oxygen physiology: sensors and ion channels," to which Gregg Semenza also contributed a review on "Regulation of carotid body oxygen sensing by hypoxia-inducible factors" [6].

Peter Ratcliffe also published early papers on hypoxiainduced gene expression in Pflügers Archiv. Certainly, Pflügers Archiv will provide a platform for research on oxygen sensing also in the future, because many important questions in the field remain to be answered. An excellent review about the past, present, and future aspects of oxygen sensing and their applications can be found in this issue of Pflügers Archiv. It has been written by Fandrey, Schödel, Eckardt, Katschinski, and Wenger who are peers in the field and also collaborators or even former fellows of the laureates.

\section{References}

1. Ivan M, Kondo K, Yang H, Kim W, Valiando J, Ohh M, Salic A, Asara JM, Lane WS, Kaelin WG Jr (2001) HIFalpha targeted for VHL-mediated destruction by proline hydroxylation: implications for O2 sensing. Science 292:464-468

2. Jaakkola P, Mole DR, Tian YM, Wilson MI, Gielbert J, Gaskell SJ, von Kriegsheim A, Hebestreit HF, Mukherji M, Schofield CJ, Maxwell PH, Pugh CW, Ratcliffe PJ (2001) Targeting of HIF-alpha to the von Hippel-Lindau ubiquitylation complex by O2-regulated prolyl hydroxylation. Science 292:468-472

3. Le Hir M, Eckardt KU, Kaissling B, Koury ST, Kurtz A (1991) Structure-function correlations in erythropoietin formation and oxygen sensing in the kidney. Klin Wochenschr 69:567-575

4. Maxwell PH, Pugh CW, Ratcliffe PJ (1993) Inducible operation of the erythropoietin 3' enhancer in multiple cell lines: evidence for a widespread oxygen-sensing mechanism. Proc Natl Acad Sci U S A 90: 2423-2427

5. Maxwell PH, Wiesener MS, Chang GW, Clifford SC, Vaux EC, Cockman ME, Wykoff CC, Pugh CW, Maher ER, Ratcliffe PJ (1999) The tumour suppressor protein VHL targets hypoxia-inducible factors for oxygen-dependent proteolysis. Nature 399:271-275

6. Prabhakar NR, Semenza GL (2016) Regulation of carotid body oxygen sensing by hypoxia-inducible factors. Pflugers Arch - Eur J Physiol 468:71-75

7. Wang GL, Semenza GL (1993) General involvement of hypoxiainducible factor 1 in transcriptional response to hypoxia. Proc Natl Acad Sci U S A 90:4304-4308

8. Wang GL, Jiang BH, Rue EA, Semenza GL (1995) Hypoxia-inducible factor 1 is a basic-helix-loop-helix-PAS heterodimer regulated by cellular O2 tension. Proc Natl Acad Sci U S A 92:5510-5514

Publisher's note Springer Nature remains neutral with regard to jurisdictional claims in published maps and institutional affiliations. 